\title{
Teaching a Master of Professional Practice in Games Development - A case study of the 'MProf' in Games Development at Abertay University
}

\author{
Ken Fee \\ Abertay University

\section{Introduction}

As game companies continue to monitor university courses with a high degree of suspicion, graduates themselves often struggle when trying to adapt to a professional, team-based, industry. This case study reflects on the key design considerations, issues and lessons learned in the development and delivery of a Master of Professional Practice (MProf) of Computer Games Development at Abertay over the five years since it started. The main focus of the discussion is the area of applied practical aptitude rather than additional research or technical skills development.

As Programme Tutor (Course Leader) responsible for the approval and delivery of 'The MProf', the author drew upon twenty years of experience as both an industrial practitioner and an academic within the field of computer games development and research, combined with interviews with students and graduates. In addition, a review of data was conducted, including assessment and grade analysis, module report forms, external examiner comments and feedback, industry mentor comments and feedback and employment destination records, in order accurately to report and comment on these aspects of the paper. Collaborations with students and academic colleagues from other institutions proved invaluable in further expanding the picture of professional practice to encompass a global as well as a national and regional context. In addition, the author consulted with representatives from a further twenty-five professional companies ${ }^{1}$, representing a cross-section of modern games development from consoles to tablet and mobile platform developers.

It is hoped that, through the employment of such a process of review and reflection, this paper portrays an informed discussion on the difficulties the games industry presents as a subject of study within this area of academic delivery and may also offer some useful insights or views as to how they may potentially be addressed.

\section{The Challenge}

As degrees in Game Study ${ }^{2}$ related areas were increasing in availability, by 2008, shortfalls in graduate ability were becoming all the more apparent as more sought to enter the industry; indeed, by 2010, the UK Government itself had asked experts in the field of games development to report on how the drain of UK-based expertise should be addressed (Livingstone Hope Review, Nesta, 2011). Further comments regarding undergraduates - as well as comments from undergraduates themselves - made it clear that graduates were

\footnotetext{
${ }^{1}$ The companies involved were Denki, TAG, Ruffian, Ninja Kiwi, Digital Goldfish, Rockstar North, Crytek, Codemasters, Travellers' Tales, Sony, Microsoft, Outplay, 4J's, Stormcloud, DICE, Blizzard, Relic, EA, EA Mobile, Blitz, Jagex, Kabam, Longtail Studios, YoYo Games and EEoGeo.

${ }^{2}$ Game Studies is the general term given to a wide range of discipline-based activities that form part of the process involved in the creation of computer games - typically interactive design, art, code, audio and marketing. Creative Skillset identifies these areas in more detail than is practical here and is available at: http://www.skillset.org/games/industry/skills/
} 
perhaps being educated in theory and rhetoric at the expense of practical skills and experience. Certainly, for reasons highlighted below, it was actually exceptionally rare for game industry practitioners to play any active role in these courses, leading inevitably to queries from both students and industry as to who exactly was teaching these courses, if no staff had ever made a game professionally. The Scottish Government, seeing the global success stories of such titles as 'Lemmings', 'Grand Theft Auto' and 'Crackdown', was also very keen to help Scotland - and Abertay - further develop and maintain its strong technical and commercial reputation within the games industry ${ }^{3}$.

A well-established and successful university in the field of games education, Abertay was the logical choice to accept these challenges, with a proven track record of programme and graduate success as well as an extremely strong network of industry supporters. The ideal solution seemed to be to create one of the first 'Master of Professional Practice' courses - in fact the first within this area of study - whose emphasis would be on graduate employability and 'real-world' behaviours that industry so craved, rather than delivery of a more traditional MSc programme which might still have focused on solitary study or theory.

This led naturally to discussion within and between the university and industrial partners ${ }^{4}$, with the aim of identifying in more detail the precise concerns about game graduates at that time, in terms of their employability. The key concerns were identified as:

1. Students' acquired working habits were very unsatisfactory, such as leaving work until the last minute, not working in a structured manner, working only on things of personal interest or within comfort zone, poor punctuality, poor communication and poor responses to direction and feedback.

2. Real-world-applicable skills and awareness were inadequate. Students chased grades or assessment criteria results, confusing a bare pass with professional competence, without acquiring deeper understanding of subject areas.

3. Ability to work within a team environment was typically very weak, with evident immaturity, and assessment potentially favoured students who relied on others to perform the collective work. An example would be where students received a single joint grade for a piece of group project work, irrespective of their individual contributions. The less conscientious students simply learned to let others to do the work, perhaps even receiving the same grade as their more diligent peers in the final assessment.

4. Students did not understand the workload expected of professionals.

5. Students arrogantly over-estimated their abilities. [In many professions, accreditation is required. Without this, many game graduates try to enter employment with little or no appreciation of how much more they have to learn, or where they may effectively perform within a professional context (Benavente, 2013).]

The identification of these key concerns allowed planning staff to distil them into three main categories, suggesting desirable learning outcomes for the programme to pursue in order to meet the goal of improved professional practice from its graduates. These areas were classified as: Industrial Conformity and Practice; Student Expectation and Behaviour; Academic Support.

\footnotetext{
${ }^{3}$ http: //www.abertay.ac.uk/about/news/newsarchive/2010/name,6277,en.html (Accessed: 12 April 2013).

4 Primarily Electronic Arts, Sony, Realtime Worlds, TAG, Denki, 4J's, Eutechnyx
} 


\section{Industrial conformity and practice}

Established research into the area of practice by renowned experts in the field, such as the work of Professor Michael Eraut, formed a sound basis for pedagogical development in this area, but inevitably, idiosyncrasies of this profession would require unique interpretation and special attention.

The main distinguishing factor of the games industry within this context was probably the somewhat troublesome fact that there were, in fact, no common working practices in the games industry. (There is no industry-wide conformity in the use of terminology, working practices or definitions - and technologies change every few months or years. While bodies such as SKILLSET and TIGA seek to standardise working practices, the industry still often reflects its chaotic origins with hobbyists and small 'bedroom-based' development teams.) A further complication was that the games industry required no qualifications whatsoever in order to practice and, while many companies preferred to employ graduates, a degree was not a universal requirement and if it was, it was more often a means of addressing work visa obligations than perceived proof of a candidate's skill superiority over others. With such failure by higher education to establish a meaningful, standardised and understood measurement of graduate skills, elements of the industry itself were often sceptical of university involvement.

\section{Student expectation and behaviour}

In terms of those who study games at university, the vast majority do so because they love playing games ${ }^{5}$. However, games development is not at all like playing them. It is the equivalent of wanting to work in a car assembly plant because of a love for driving fast. It may take years to develop a game that takes only a few hours to play through - and the skills required to make a game bear no relation to the consumer experience. In terms of employability, the enthusiasm or passion of the graduate was far too dependent on his/her level of personal interest in the project at hand, even though that project could change at any time.

In 2009, Abertay Game Design and Production Management students asked Gordon Brown, visiting lecturer and character artist, what he had felt like the first time he had played Grand Theft Auto 4, having worked on it for three years. He told them that he hadn't even opened the box; he'd spent up to sixty hours a week for three years poring over it in development and the last thing he wanted to do was play it. This shocked the students, but is absolutely typical of a professional's attitude.

The logical question for the programme staff then became: If it's not for the fun of it, what behaviours should the students actually have that are most suited to a successful career in games development? Similarly, if students wished better to understand and research the field of practice from an academic perspective, how should they best be supported?

\footnotetext{
${ }^{5}$ Student interviews conducted in 2009, 2010 and 2011 by the author at Abertay, Cumbria and Birmingham City Universities, revealed a love for playing games as being the prime factor in their decision to study games.
} 


\section{Academic support}

This area of games development is the largest in the world in terms of commercial value (Charlton, 2012), but it still suffers in perceived cultural or intellectual value. The explosion of computer games courses in the last decade may well be more attributable to issues related to student recruitment than to a more widespread social acceptance of games as a truly valuable, cultural art form. Additionally, in an industry that is still quite young and exists without the need for any academic qualifications to practice, where should subjectcompetent and qualified lecturing staff come from? While educational establishments have QAA regulations and protocols to follow to ensure that teaching and research staff are appropriately qualified, in practice this often means that very experienced game developers, who may have left school with few if any formal qualifications, but then worked in the games industry for twenty years, would have no academic credentials whatsoever. Conversely, a young lecturer may have several degrees, but has never made a game; if trying to represent such a volatile and fast-moving industry, how could such a lecturer offer effective advice without any practical experiences of his/her own?

\section{Pedagogical Development}

Once these three main areas of concern had been identified, the focus of the programme design team became the consideration of how they could be addressed within a pedagogical framework. While other core modules within the programme would focus on Innovation and Research, Games Industry Awareness and Narrative Theory, a single module - worth 60 of the 180 credits required for the Master's qualification - was named simply 'Games

Development'. This module would focus on professional team-based games development, in response to a variety of different projects and using various technologies, and, each semester, offer students the opportunity to experience the impact of different team sizes and creative control. The students would initially work in teams of two or three on ideas of their own and then, in teams of five or six, on ideas sanctioned by others and finally, in teams of ten to fifteen students, on live projects from clients. Each project shift in team size and creative autonomy would allow them to experience and understand better the typical working practices of their professional counterparts. This module in particular would address the elements which consultation had shown to be of paramount importance, through the following guiding principles:

\section{1) The importance of mentor involvement and guidance}

Mentors (whether in person or remotely) would assist lecturers with module content and student support - not only for relevance of teaching materials, but also to demonstrate to the students that there existed an unquestionable level of genuine parity with industry expectation. In practice, it was occasionally the case that students who had performed well at undergraduate level - where perhaps theory or self-directed work was the focus - would stumble when turning to professional practice. Such students could then develop a very negative attitude to both the programme and the staff, especially if they were used to being held in particular esteem by their peers in earlier programmes of study. Once this dynamic arose, it could prove very challenging to resolve, with the potential for a student to perceive his/her assessment as destructive rather than constructive feedback, coming as it did from a different academic perspective from what they might have experienced before. 
Under such circumstances, mentors could provide additional support to the teaching staff by delivering feedback directly to students and allowing the teaching staff to step back into a support and guidance role, helping the student to interpret the feedback and guiding him/her to focus upon solutions.

\section{2) Individual assessment within teams}

On many occasions, student teamwork is a source of great frustration for the best students and an easy ride for the worst, and this problematic inconsistency is compounded if they are all given a single combined summative team grade ${ }^{6}$. In the response to this typical dynamic, in the Games Development module, teams of students would work on games, but the games themselves would not be marked - they were just the means to an end, a framework on which behaviours could be developed and assessed. Everyone within the team was assessed individually during the exercise of creating the game, against several key skills identified by industry practitioners as core to effective team-working (adapted from quite established academic theory in this area):

i) Practical and meaningful role within a game development team.

ii) Ability to apply and evaluate suitable techniques and approaches to game development within a team.

iii) Ability to evaluate problems critically, drawing valid conclusions from the available evidence.

iv) Ability to identify their own strengths and weaknesses and possible areas for improvement.

v) Level of proven ability, working in a team, to produce artefacts that are appropriate for Masters Level study.

vi) Effective communication skills as appropriate to their discipline.

It is perhaps now clear how some students may find themselves receiving very different feedback from that received during their undergraduate course.

\section{3) Remove or mediate control}

In reality, few professionals spend their whole working lives on projects which satisfy their own passions and interests and they are very rarely in control of their work allocation.

Chris Goodswen, Lead Character Artist at Crytek, offers a typical comment in this regard,

[placement students] were shocked to hell as they thought that being a

character artist was all sculpting and making pretty characters...oh how they were wrong!'

However, this is the exact opposite of a typical undergraduate experience, where students usually pursue an area of enquiry that most interests them and develop that in their Honours year.

\footnotetext{
${ }^{6}$ Conclusions reached following author's discussion with undergraduate students, teaching staff and the external examiner at Abertay University during August 2009 and June 2010, following project work undertaken by some 150 students across approximately 20 projects.
} 
In professional practice, it must be the actual process that the student enjoys and wants to pursue rather than the sense of personal control or ownership over what that artwork or mechanic actually is. If this is not the case, then the value of the graduate as an employee will be wholly dependent on just how much an individual project appeals to him/her and that is certainly not a sound basis for full-time employment by a studio. The same premise applies for freelancers, as the likelihood that they will be able to support themselves continuously by moving freely from one project of personal interest to another is remote (at least until they have made a reputation for themselves, so that the industry actually seeks them out as individuals of note).

In terms of the module and execution, then, this translated into the following project brief requirements:

i) Students must work in a timely and focused manner, showing constant progress or reflection on a daily basis, and on occasion be asked to follow directions whether they agree with them or not.

ii) They are not allowed to set their own hours or tasks, but rather follow schedules.

iii) They must adhere to identified roles and responsibilities.

iv) They must work together, with workspaces provided.

v) The client, not the students, will determine the quality of their work.

\section{4) Feedback and review - reflective practice in action}

A single summative grade model would just confirm to students their assessed ability, but with no opportunity to learn how to improve (Moon, 2006). Formative feedback, on the other hand, allows for constant reflective practice, with students receiving direction and feedback every few days and thereby being able to demonstrate constant development in terms of their professional competencies.

In addition, the module would make use of peer review, whereby team members would give feedback on one another based upon observations of professional behaviour such as communication, response to request for changes or feedback. While these reviews would not play a direct part in assessment, they would help students to understand how they were perceived within a team environment and allow module staff to offer more personalised reviews of their performance and support as required. The students providing the peer reviews were, of course, under examination as much as the peers they were discussing, to ensure that they understood how to regard others' behaviours in a professional context and report on them accordingly.

For example, in one cohort, students who were friends, but were struggling professionally, considered that one way of avoiding an unfavourable grade was for each to give a glowing appraisal of the other. One sought to explain that he had worked well and that it was actually the fault of another student that his design contribution was not correctly implemented, but he then proceeded to give that other student a glowing review. Ultimately, this resulted in the designer's receiving a poor assessment, both for his work and for his inability to review others' work in a professional manner. 
Similarly, the students were directed to avoid either commenting on the perceived skill levels of their colleagues or using scores, being asked instead to focus on short statements regarding each of the key skills. Students had begun to term one another 'extremely professional' and yet, within the context of professional practice, they were not qualified to do so. Instead, the students should have commented on the very team-work skills we were looking for, such as communication, willingness or ability to collaborate and so forth. In general, feedback remains the most contentious area - particularly for students who may have achieved first class honours at undergraduate studies. It transpired in this study that many, but by no means all, first class undergraduates had excelled in theory, but had almost no skills related to genuine practice. When asked to operate as professionals, they struggled the most. [This observation in itself is nothing new, Professor Georgina Follett of Duncan of Jordanstone Art School (DJCA) at Dundee University having offered the opinion at a School review of DJCA as far back as 2005 that '... lower second class honours students are actually the most successful in professional practice.'] In addition, these students often have the most to lose in terms of peer respect and reputation, so often resist the most against what they regard as unexpectedly unfavourable or unflattering feedback, no matter how unanimous staff have been in their judgement or how incontrovertible it is as objective assessment of their performance.

\section{5) A focus on team goals over individual gain}

While all students must be assessed individually (just as they would be employed as individuals, though then deployed to work in a team), the actual focus of their efforts must be for 'the greater good' - that is, the project.

The irony is that each and every one of the separate disciplines within a game team often has a slightly different goal in mind.

The artists want the game to be visually stunning, but then it may run slowly and take up more memory than the programmers feel is appropriate, as, in turn, the programmers want the game to run as fast - and with as much stability - as possible. Designers, on the other hand, may want the game to be complex, yet the testers want all design locked down quickly and producers want the game completed last week! The client (in this case, possibly teaching staff) wants the game to be in under budget in terms of time and resources and act as a draw for future investment / student recruitment.

It is of prime importance that students develop an understanding of the part they play in a bigger picture and are capable of making compromises and collaborative acts of sacrifice.

\section{6) Industrial placements}

Industry placements were not necessarily of as much value as one might expect, at least within this particular area of professional practice. In many areas of industry, a company may well have its own way of operating, based upon a relatively established set of industry procedures and expectations and often derived from an extensive period of professional practice on which to reflect. The games industry, however, is so new and so chaotic that such established practices are very unlikely to be enshrined effectively in any one institution. It might be preferable to offer multiple short-term placements to obviate this, but the demands this would place on industrial support - a finite resource at best - and on academic monitoring would likely render the approach impractical. In addition, as Mike McShaffry (2009) notes, the instability of computer games companies, coupled with the purely 
commercially-driven and potentially ethically-challenging nature of many of the projects, means that placements often present more challenges for HE collaboration than solutions. If staff within companies act as mentors - instead of the companies themselves - most of these concerns may be obviated, as these individuals retain their experience and value even if a company itself ceases trading.

In a university setting - with proper mentor support from across a range of companies and locations - students have the opportunity to gain a far wider exposure to the industry as a whole. Mike Cummings (2011), an MProf graduate, concurs:

'The greatest value was just watching a group of industry folk talk about our game in front of us, talking freely between themselves - the observations and thought processes flowed in a brilliant conversation, it was awesome.'

This is not so say such collaborations should be avoided, but they should be very carefully judged on a case-by-case basis; often, mentors appointed from these companies, each of whom being just one voice amongst dozens of mentors, do present a better solution, in ensuring that the students receive a truly industry-wide awareness of expectations and practices. The combination of close industrial ties and industry-experienced teaching staff working in close support of theoretical and research-based colleagues has meant that the MProf programme this year at Abertay has sixty mentors available to the students. Importantly, it is not necessarily the industrial expertise of the ex-industry staff on the programme that plays the key part in obtaining such support (though all sixty mentors have been organised through them), but rather their ability to access the connections and networks they managed to build up during their former period of industrial practice.

\section{Reflections and summary}

For the author as an educator, the programme - and the core games development module in particular - has been a fascinating experience to be involved with. The difference between undergraduate students, albeit technically skilled, and what they must become to meet the far broader expectations placed on professional developers, has been clarified with every cohort, mentor visit and industry collaboration. The students themselves typically report during their studies that it is the hardest period of study they have ever experienced, yet, once in employment and asked to reflect back on their experience, they often comment that they had no idea just how easy the course was in comparison with their current work. This is never intended as a criticism of the course - nor is it taken as one - yet it is a further indicator of just how far removed some courses in the subject area are from genuine professional practice. The original programme was designed when console development was still the mainstay of professional games development, but, in the five years since its approval, the programme has had steadily to adjust to mobile, tablet and social gaming. The careful design of the core modules' learning outcomes has meant that the design of the modules themselves has never needed to change, but the projects that were employed within them have had to. The key skills required for successfully working in a team discussed above - do not change, regardless of the platform the game is developed for.

The core professional attributes such as communication, adaptability and team work have not changed either and, with these forming the basis of the pedagogical model, the 
programme staff themselves, as well as the industrial mentors, visiting lecturers and associated academic colleagues, face the programme's future with a large degree of confidence; however, they all remain very aware of just how dynamic the industry under focus is and how important it is to avoid complacency in order to ensure that the ultimate goal of the programme - the enhancement of students' ability to evolve seamlessly from student into practitioner - continues to be met by preparation of the highest possible quality.

When the programme was undergoing validation approval in 2009, Colin Anderson, CEO of Denki, and Colin MacDonald, Studio Manager of Realtime Worlds, external consultants on the approval board, claimed that, '...this is the course the industry has been waiting for.' Clearly, these were very positive words and, though it has required constant work to ensure that the lectures, assignments and assistance from industry remain relevant, the programme is currently hosting its fifth cohort of students and the last destination data - covering the year graduating in 2012 - suggest that all bar one of the forty is now employed in the games industry or a closely-related discipline. Whilst these are very satisfying results, they can be achieved only by dedicated team-work by educators, mentors and industry advisers; they are nevertheless indicative of an effective pedagogical model that, it is to be hoped, will remain relevant for many years to come.

\section{References}

Benavente, E. (2013) Interviewed by Kenneth Fee, Abertay University, April 2013.

Cummings, M. (2011) Interviewed by Kenneth Fee, Abertay University, February 2011.

Charlton, A (2012) 'Video Games Outsell DVDs to Become Biggest Entertainment Category'. International Business Times (22 March 2012 11:52 BST) Available at:

http://www.ibtimes.co.uk/video-game-biggest-entertainment-category-uk-317940 (Accessed: 14 August 2014).

Eraut, M (1994) Developing Professional Knowledge And Competence. London, Falmer Press.

Livingstone, I. and Hope, A. (2011) The Livingstone Hope Review, NESTA, London.

Goodswen, C. (2013) Interviewed by Kenneth Fee, Abertay University, May 2013.

McShaffry, M (2009) Game Coding Complete. Hingham, Massachusetts, Charles River Media.

Moon, J.A. (2006) Learning Journals: A Handbook for Reflective Practice and Professional Development, $2^{\text {nd }}$ edition. New York, Routledge. 